Article

\title{
Comparison of Theoretical and Laboratory Out-of-Plane Shear Stiffness Values of Cross Laminated Timber Panels
}

\author{
Jan Niederwestberg ${ }^{1, *}$, Jianhui Zhou ${ }^{2} \mathbb{D}$ and Ying-Hei Chui ${ }^{1}$ \\ 1 Department of Civil and Environmental Engineering, University of Alberta, \\ Edmonton, AB T6G 1H9, Canada; yhc@ualberta.ca \\ 2 Integrated Wood Engineering, University of Northern British Columbia, \\ Prince George, BC V2L 1R6, Canada; jianhui.zhou@unbc.ca \\ * Correspondence: jan.niederwestberg@ualberta.ca
}

Received: 21 September 2018; Accepted: 19 October 2018; Published: 22 October 2018

check for updates

\begin{abstract}
The lay-up of cross laminated timber (CLT) leads to significant differences in properties over its cross-section. Particularly the out-of-plane shear behavior of CLT is affected by the changes in shear moduli over the cross-section. Results from laboratory shear tests are used to evaluate the shear stiffness of 3- and 5-layer CLT panels in their major and minor strength direction. The results are compared to calculated shear stiffness values on evaluated single-layer properties as well as commonly used property ratios using the Timoshenko beam theory and the shear analogy method. Differences between the two calculation approaches are pointed out. The shear stiffness is highly sensitive to the ratio of the shear modulus parallel to the grain to the shear modulus perpendicular to the grain. The stiffness values determined from two test measurements are compared with the calculated results. The level of agreement is dependent on the number of layers in CLT and the property axis of the CLT panels.
\end{abstract}

Keywords: cross-laminated timber (CLT); out-of-plane shear stiffness; Timoshenko beam theory; shear analogy method; rolling shear modulus

\section{Introduction}

In recent years cross-laminated timber (CLT) gained popularity all over the world. Due to CLT's lay-up with alternating grain orientation of adjacent layers CLT shows high in- and out-of-plane stiffness and two-way action behavior when used as a plate which allows CLT to be used in both wall and floor applications. As well, the cross-section is not homogeneous and special attention has to be given to the arrangement when designing CLT. The different layer orientations affect the overall stiffness as well as the stresses within the cross-section. Particularly the shear properties of CLT are influenced by the existence of the transverse layers. The transverse layers experience shear perpendicular to the grain, so called rolling shear, when exposed to out-of-plane bending. As a result of this and the low shear strength perpendicular to the grain, rolling shear failures are one of the most common failure modes of CLT panels [1]. Several studies have investigated parameters that affect the rolling shear strength of CLT panels. O'Ceallaigh et al. (2018) [2] tested the bending and shear strength of 3- and 5-layer CLT with different panel thicknesses. The study found that both, bending and rolling shear strength decreases with increasing panel thickness. While the number of layers showed no effect on the rolling shear strength, the bending strength increased with an increasing number of layers. Ehrhart et al. (2015) [3] tested the rolling shear properties of individual boards to evaluate the effects of the location of a board within a log as well as the board geometry. It was found that boards from locations closer to the pith show a higher rolling shear modulus and that rolling 
shear modulus and strength increase with increasing aspect ratio (width-to-thickness of the laminate). The relatively low rolling shear modulus can affect the deformation behavior of CLT significantly. Therefore, the shear deformation should be included when calculating the total panel deflection. There are several methods available to calculate the stiffness properties of CLT, some of them being capable of accounting for the effects of shear deformation. The most commonly used methods accounting for the shear deformation are the "Mechanical Jointed Beams Theory" as it can be found in Eurocode 5 [4], the "Timoshenko Beam Theory" with an adjusted shear correction factor [5] and the "Shear Analogy Method" [6]. For laminated composites such as CLT the shear correction factor is dependent on the lay-up of the composite and the layer properties. The shear correction factor for laminated composites can be determined based on the energy principle [7].

To show the effects of shear on the behavior of CLT panels, the results from two of the methods mentioned above, namely the shear analogy method and the Timoshenko beam theory with adjusted shear correction factor, are presented. Actual single-layer properties are used as the basis for these calculations. The calculated results are compared with laboratory test results from 3- and 5-layer CLT panels that were formed from the single-layer panels used in the calculations. The agreement of the two calculation approaches is discussed. Further, the sensitivity of the calculation approaches to different $G_{13} / G_{23}$ ratio is presented.

\section{Methodology}

Three different methods for the determination the shear stiffness values of CLT panels under out-of-plane loading are employed and compared. These are two theoretical methods and a laboratory test approach.

\subsection{Theoretical Methods}

A general overview of the two theoretical methods, namely the Timoshenko beam theory and the shear analogy method, used in the comparison is presented in this section.

\subsubsection{Timoshenko Beam Theory}

Timoshenko beam theory is commonly used for the calculation of beam deflection when the shear deformation is considered. The Timoshenko beam theory addresses the shear deformation using a shear form factor. The shear form factor compensates for the assumption of a constant shear strain over the cross-section. The shear correction factor is the reciprocal value of the shear form factor and is defined as the average shear strain within a section to the shear strain at its centroid [8]. Timoshenko suggested shear correction factor of $2 / 3$ for isotropic solid homogeneous isotropic beams with rectangular cross-sections [8] but commonly used values are 5/6 (Reissner) [9], $\pi^{2} / 12$ (Mindlin) [10], or values as a function of the Poisson's ratio (Cowper) [11]. The lay-up with the alternating grain orientation of CLT leads to a more complicated transverse shear strain distribution and therefore the values mentioned above are not applicable for CLT.

The overall bending and shear stiffness are calculated based on the properties of the layers and their location within the arrangement. The effective bending stiffness $(E I)_{e f f}$ is calculated by the sum of inherent bending stiffness of the individual layers along their own neutral axis and the sum of stiffness contribution of each layer based on Steiner's theorem (parallel axis theorem), as it can be seen in Equation (1).

$$
(E I)_{e f f}=\sum_{i=1}^{n}\left(E_{i} \cdot I_{i}\right)+\sum_{i=1}^{n}\left(E_{i} \cdot A_{i} \cdot z_{s, i}^{2}\right)=\sum_{i=1}^{n}\left(E_{i} * \frac{b_{i} \cdot t_{i}^{3}}{12}\right)+\sum_{i=1}^{n}\left(E_{i} \cdot b_{i} \cdot t_{i} \cdot z_{i}^{2}\right)
$$

where $E_{i}$ is the modulus of elasticity of the $i$-th layer, $b_{i}$ is the width of the $i$-th layer and $t_{i}$ is the thickness of the $i$-th layer. The coordinate $z$ has its origin in the cross-section's neutral axis and is 
directed normal to the panel face as defined in Figure $1, z_{i}$ is the distance between the center point of the $i$-th layer and the overall neutral axis.

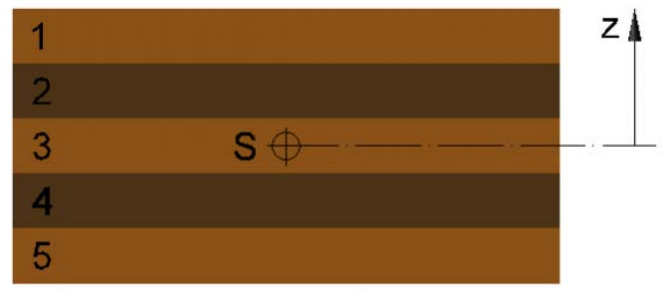

Figure 1. Definition of coordinate $z$.

Within the Timoshenko beam theory, the effective shear stiffness is calculated by adjusting the shear stiffness, $(G A)_{e f f}$, with the so-called shear correction factor $\mathrm{k}$ (see Equation (2)). The shear correction factor compensates for the assumption of a constant shear strain across a cross-section.

$$
(G A)_{e f f}=\kappa \sum_{i=1}^{n} G_{i} \cdot A_{i}=\kappa \sum_{i=1}^{n} G_{i} \cdot b_{i} \cdot t_{i}
$$

where $\mathrm{k}$ is the shear correction factor, $G_{i}$ is the shear modulus of the $i$-th layer, $b_{i}$ is the width of the $i$-th layer and $t_{i}$ is the thickness of the $i$-th layer.

As mentioned before, the shear correction factor commonly used for solid isotropic rectangular cross-sections is not applicable to CLT due to the alternating lay-up and the resulting stepwise strain distribution. Augustin et al. (2010) [5] proposed a shear correction factor for CLT, KCLT $_{\text {. The CLT }}$ related shear correction factor is calculated based on Equations (3) and (4).

$$
\begin{gathered}
\kappa_{C L T}=\frac{1}{\kappa_{z}} \\
\kappa_{z}=\frac{\sum G A}{\left((E I)_{e f f}\right)^{2}} \int_{h} \frac{\left[E_{(z)} \cdot \int A_{(z)} \cdot z d z\right]^{2}}{G_{(z)} \cdot b_{(z)}} d z
\end{gathered}
$$

where $\mathrm{K}_{z}$ is the shear correction coefficient, $\sum G A$ is the sum of the shear stiffness of the overall cross-section, $E_{(z)}$ is the modulus of elasticity, $A_{(z)}$ is the considered cross-sectional area, $G_{(z)}$ is the shear modulus, $b_{(z)}$ is the width of the section, $z$ is the distance of the considered location to the cross-section neutral axis. Subscript $(z)$ refers to the property with respect to coordinate $z$. Combining Equations (2) and (3) leads to the equation for the determination of the effective shear modulus $(G A)_{\text {eff }}$ for the Timoshenko beam theory with an adjusted shear correction factor (Equation (5)).

$$
(G A)_{e f f}=\kappa_{C L T} \sum_{i=1}^{n} G_{i} \cdot A_{i}=\kappa_{C L T} \sum_{i=1}^{n} G_{i} \cdot b_{i} \cdot t_{i}
$$

where $\kappa_{C L T}$ is the shear correction factor for CLT, $G_{i}$ is the shear modulus of the $i$-th layer, $b_{i}$ is the width of the $i$-th layer and $t_{i}$ is the thickness of the $i$-th layer.

\subsubsection{Shear Analogy Method}

The shear analogy method was developed by Kreuzinger [6]. The method considers the different moduli of elasticity and shear moduli of the individual layers for nearly all system configurations (e.g., number of layers, span-to-depth ratios). The bending stiffness of a CLT panel is calculated using the same equations as presented in the Timoshenko beam theory section (Equations (1)). The effective shear stiffness is calculated based on the assumption that the connection between adjacent layers is rigid i.e., no slip deformation occurs in the glue line. Commonly the effective shear resistance is 
calculated based on the distance between the center points of the two layers orientated parallel to the considered direction that are the furthest apart from each other. Equation (6) presents the calculation of the effective shear stiffness $(G A)_{e f f}$ in the major direction of a CLT panel.

$$
(G A)_{e f f}=\frac{(a)^{2}}{\frac{t_{1}}{2 \cdot G_{1} \cdot b_{1}}+\sum_{i=2}^{n-1} \frac{t_{i}}{G_{i} \cdot b_{i}}+\frac{t_{n}}{2 \cdot G_{n} \cdot b_{n}}}
$$

where $a$ is the distance between the centre points of the most outer layers parallel to the considered direction, $G_{i}$ is the shear modulus of the $i$-th layer, $b_{i}$ is the width of the $i$-th layer and $t_{i}$ is the thickness of the $i$-th layer.

\subsection{Laboratory Tests}

Modal and static laboratory tests were carried out to evaluate the effects of shear on out-of-plane bending performance of 3- and 5-layer CLT panels. The 3- and 5-layer CLT panels were formed from "homogeneous" single-layer panels. The single-layers were formed from laminates with similar modulus of elasticity and shear modulus, which were evaluated using a modal testing approach developed by Chui [12].

The grouped laminates were glued together to form fully-edge-glued (FEG) and semi-edge-glued (SEG) single-layer panels. FEG-layers were formed by laminates glued together over the whole length of the laminates using a one-component structural polyurethane adhesive. SEG-layers were formed by laminates glued together with a minimum of local glue spots. SEG-layers were used to simulate non-edge-glued layers, the minimum local glue area was needed to enable the structure to be tested as a layer. The grouping of the laminates by elastic modulus, shear modulus led to "homogenized" layers with similar laminate characteristics. The single-layer panels were tested in modal and static tests to evaluate their modulus of elasticity parallel to the grain $\left(E_{11}\right)$ and perpendicular to the grain $\left(E_{22}\right)$ (FEG-layers only) and in-plane shear modulus $\left(G_{12}\right)$.

After the completion of the single-layer tests the layers were cut in half before being face-glued to form 3- and 5-layer CLT panels using the same one-component structural polyurethane adhesive as before. All layers within a CLT panel had the same edge-gluing type. To ensure that the CLT panels had a truly symmetrical layup, layers at the same distance from the middle layer within a CLT panel were obtained from the same initial rectangular layer. Again, modal and static tests were carried out to evaluate the global $E_{11}, E_{22}$ and $G_{12}$ values as well as the major and minor planar shear moduli $\left(G_{13}\right.$ and $G_{23}$ ) of the 3- and 5-layer CLT panels. Besides the FEG and SEG layer based 3- and 5-layer panels, some 3-layer panels with both FEG and SEG layers were formed, Mix-FSF (FEG layers on the outside, SEG layer on the in the core) and Mix-SFS (SEG layers on the outside, FEG layer on the in the core). As before these lay-ups were symmetrical about its geometric centroid.

\subsubsection{Material and Conditioning}

Wooden boards (mainly spruce) with various characteristics were conditioned to a moisture content of about $13 \%$. To facilitate further processing, all boards were sized to constant dimensions after conditioning. The boards had a length of $1500 \mathrm{~mm}$, a width of $128 \mathrm{~mm}$ and a thickness of $19 \mathrm{~mm}$. In order to maintain the achieved moisture content during further processing and testing, the material was stored in a conditioning chamber maintained at $20^{\circ} \mathrm{C}$ and $65 \%$ relative humidity.

In order to create "homogeneous" groups of laminated from the wooden boards, the modulus of elasticity $(E)$ and the shear modulus $(G)$ of boards were determined by use of a free-free beam modal testing approach as described by Chui [12]. The free-free boundary conditions were achieved by suspending the specimen with strings in a vertical position from a rigid steel frame. The strings with low stiffness would allow the specimen to vibrate as though it is freely suspended in space. The application of the Timoshenko beam theory led to derivation of a frequency equation that relates a natural frequency to $E$ and $G$ [12]. It follows that simultaneous measurement of the first and second 
natural frequencies led to two equations with two unknowns, $E$ and $G$. In a test, the specimen was excited by an impact hammer and the vibration response was measured by an accelerometer. Based on the laminate natural frequencies, dimensions and density, the $E$ and $G$ of the test specimen were calculated. More information on the procedure and theoretical basis of the test method can be found in Chui [12]. Figure 2 shows the test setup for the modal free-free beam tests.

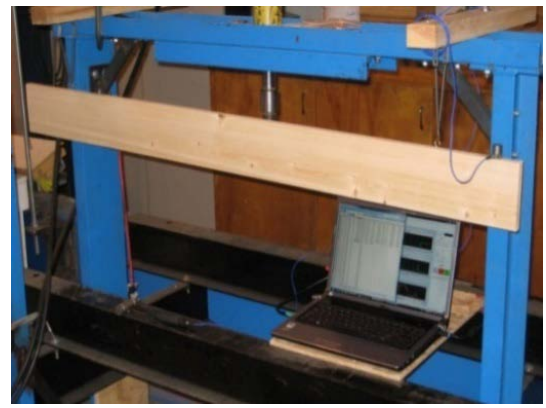

Figure 2. Modal free-free beam test setup, laminate suspended with strings.

\subsubsection{Modal Panel Tests}

Modal panel tests were carried out during the single-layer and CLT panel phases. The tests were carried out in free-free boundary conditions which has no closed form solution. The natural frequencies and the related mode shapes were measured over a six-by-six impact point grid. Since there is no closed form solution, the elastic constants $E_{11}, E_{22}$ and $G_{12}$ were determined in an iterative process using finite element (FE) analysis as proposed by Larsson [13]. The commercial software Abaqus was used for the FE analysis. In the process, the three elastic constants were adjusted successively until experimental and analytical natural frequencies and related mode shapes $\left(f_{1,1}, f_{2,0}\right.$ and $\left.f_{0,2}\right)$ matched. A FE model resembling the test setup was developed. The single-layer panel was modelled as a shell element while the CLT panels were modeled as a 3D solid element. The free-free boundary conditions were achieved by two supports at the locations of the strings. Figure 3 shows the modal test setup (a) and the FE model of a single-layer panel (b).

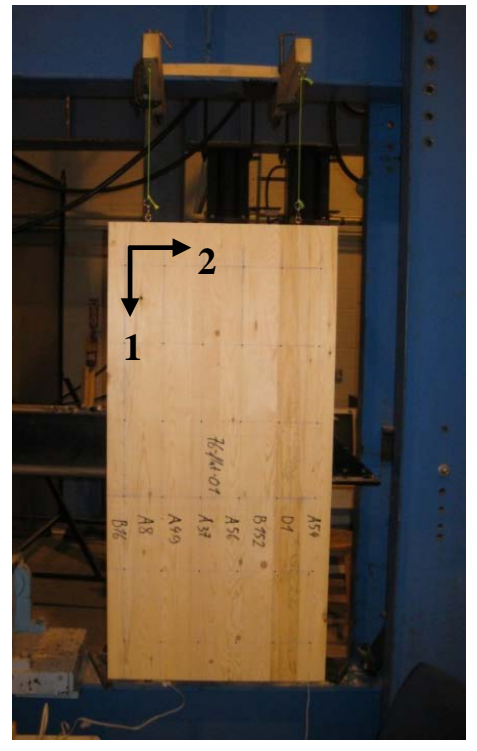

(a)

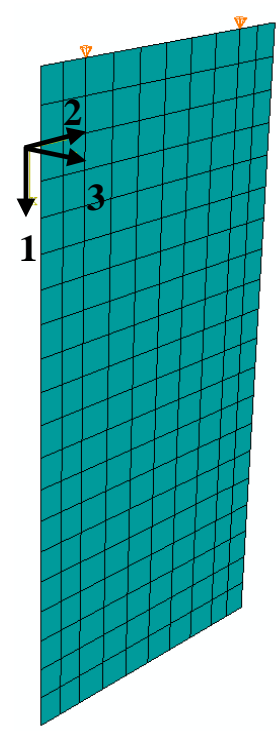

(b)

Figure 3. Modal panel tests (here: single-layer): (a) Laboratory test; (b) Finite element model. 


\subsubsection{Bending Tests}

Three-point bending tests in accordance to ASTM D198 [14] were carried out in order to evaluate the $E_{11}$ values of single-layer and CLT panels. Furthermore, the $E_{22}$ values of the FEG panels were evaluated. The $E_{22}$ values of the SEG single-layer panels were not evaluated since the local spot gluing of the SEG layers did not provide enough stability to perform bending tests perpendicular to the grain. The deflection was measured by two linear variable differential transformers (LVDTs), located at the center of the span and $100 \mathrm{~mm}$ in from each edge. The two measurements from the LVDTs were averaged for the calculation of the $E$ values. Figure 4 shows the test setup for the $E_{11}$ evaluation of a single-layer panel. Table 1 gives the test span, span-to-thickness ratios and displacement rates of the different test phases.

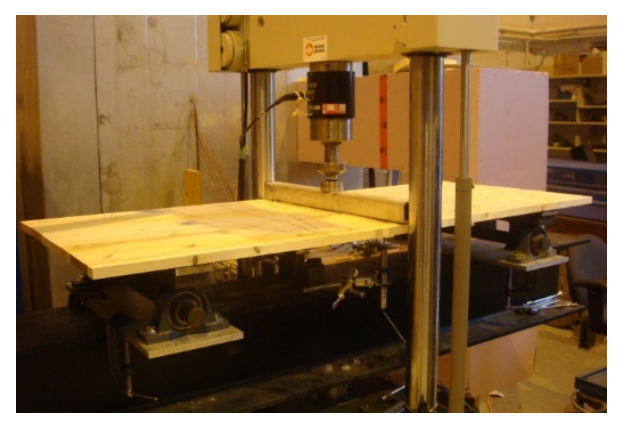

Figure 4. Three-point bending test (here: $E_{11}$ value of a single-layer).

Table 1. Information of three-point bending tests.

\begin{tabular}{|c|c|c|c|c|}
\hline Panel & Elastic Moduli & Span $(\mathrm{mm})$ & Span-to-Thickness & $\begin{array}{l}\text { Displacement } \\
\text { Rate (mm/min) }\end{array}$ \\
\hline \multirow{2}{*}{ Single-Layer } & $E_{11}$ & 1100 & 57.9 & 8.0 \\
\hline & $E_{22}$ & 500 & 26.3 & 0.75 \\
\hline 3-Layer CLT & $\begin{array}{l}E_{11} \\
E_{22}\end{array}$ & 500 & $10.3-10.8$ & 0.5 \\
\hline 5-Layer CLT & $\begin{array}{l}E_{11} \\
E_{22}\end{array}$ & 500 & $6.2-6.7$ & 0.5 \\
\hline
\end{tabular}

In accordance with ASTM D198 [14], the apparent moduli of elasticity $E_{a p p}$ of the panels were evaluated using the load-deformation response measured during the three-point bending tests. Equation (7) shows the determination of $E_{a p p}$ for a three-point bending test.

$$
E_{\text {app }}=\frac{P l^{3}}{4 b t^{3} \Delta}
$$

where $P$ / $\Delta$ is the slope of the load-deformation curve, $l$ is the span, $b$ is the width of the specimen and $t$ is the thickness of the specimen.

\subsubsection{Planar Shear Tests}

Selected single-layers, as well as 3- and 5-layer CLT panels were tested in planar shear tests in accordance with ASTM D2718 [15]. In the tests, the global planar shear moduli in the major and minor directions of the CLT panels $\left(G_{13}\right.$ and $G_{23}$ ) were evaluated. Samples in both directions, parallel and perpendicular to the grain of the outer layers, were cut from the CLT panels. The specimens had a length of $400 \mathrm{~mm}$ and a width of $152 \mathrm{~mm}$. Two aluminium plates were glued to the two faces of the test specimen using a two-component epoxy adhesive. After the application of the epoxy adhesive the specimens were cured under a pressure of $0.8 \mathrm{~N} / \mathrm{mm}^{2}$ in an environment with a temperature above 
$20{ }^{\circ} \mathrm{C}$ for at least $12 \mathrm{~h}$. In the test, a load was applied to the aluminum plates at a displacement rate of $0.5 \mathrm{~mm} / \mathrm{min}$. The relative displacement between the two aluminum plates during the tests were measured by two LVDTs. The recorded displacement was used to determine the global shear moduli of the CLT panels. The test setup can be seen in Figure 5.

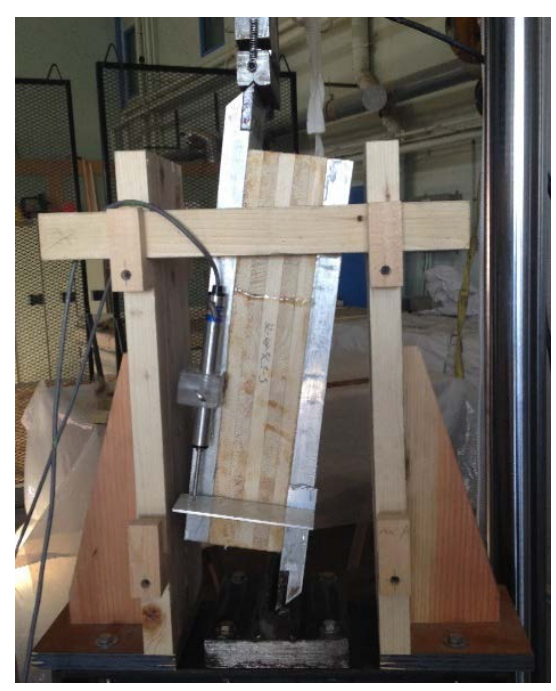

Figure 5. Planar shear tests for the $G_{13}$ and $G_{23}$ evaluation (here: $G_{13}$ of a 5-layer CLT panel).

ASTM D2718 is intended for testing of relatively thin panels, like plywood. Testing of thick panels, such as CLT, leads to a relatively large angular rotation of the specimen and therefore an alignment between the applied load and the CLT panels major/minor direction. Due to this the results from the tests needed to be corrected by multiplying the results with the cosine of the angle of the specimen. The correction factor was calculated based on Equation (8).

$$
k_{\alpha}=\cos \left(\tan ^{-1}\left(\frac{t / 2}{l_{\text {plate }}-l / 2}\right)\right)
$$

where $k_{\alpha}$ is the correction factor for the angle of the specimen, $t$ is the thickness of the specimen, $l_{\text {plate }}$ is the length of the aluminium plates including the knife edge and $l$ is the length of the specimen.

The planar shear moduli $\left(G_{13}\right.$ and $G_{23}$ ) were calculated by Equation (9). The equation is based on equations that can be found in Reference [15].

$$
G_{13} \text { or } G_{23}=\frac{P t}{l b \Delta} \cdot k_{\alpha}
$$

where $P / \Delta$ is the slope of the load-deformation behavior, $b$ is the width of the specimen and $k_{\alpha}$ is the correction factor for the angle of the specimen as defined in Equation (8).

The shear stiffness of the multi-layer CLT based on the planar shear test, $(G A)_{\text {planar }}$, can be calculated based on Equation (10).

$$
(G A)_{\text {planar }}=G_{13} A \text { or } G_{23} A
$$

where $A$ is the overall cross-sectional area of the multi-layer CLT panel in the corresponding direction. 


\subsubsection{Evaluation of the Effective Shear Stiffness}

Besides the equation for the apparent modulus of elasticity, $E_{a p p}$ (Equation (7)), ASTM D198 [14] provides an equation for the evaluation of the shear-free modulus of elasticity. Equation (11) shows the calculation for the determination of a shear-free modulus of elasticity $E$ in three-point bending.

$$
E=\frac{P l^{3}}{4 b t^{3} \Delta\left(1-\frac{3 P l}{10 b t G \Delta}\right)}
$$

where $P / \Delta$ is the slope of the load-deformation curve, $l$ is the span between the supports, $b$ is the width of the specimen, $t$ is the thickness of the specimen and $G$ is the shear modulus in the corresponding direction.

Rewriting Equation (11) by applying the Timoshenko shear correction factor $\mathrm{\kappa}(5 / 6$ for rectangular cross-sections) and replacing $k b t G$ with $(G A)_{e f f}$ (Equation (5)) leads to Equation (12).

$$
E=\frac{P l^{3}}{4 b t^{3} \Delta\left(1-\frac{P l}{4 \cdot(G A)_{e f f} \Delta}\right)}
$$

The equation for the apparent moduli of elasticity, $E_{a p p}$ (Equation (7)) can be substituted into Equation (12). Rearranging Equation (12) afterwards the effective shear stiffness $(G A)_{\text {eff }}$ can be calculated under the assumption that the effects of shear on the moduli of elasticity evaluated by the modal tests, $E_{\text {modal }}$, are negligible. Equation (13) shows the calculation of the effective shear stiffness from flexure tests, $(G A)_{\text {eff, flex }}$.

$$
(G A)_{e f f, f l e x}=\frac{P l}{4 \Delta\left(1-\frac{E_{a p p}}{E_{\text {modal }}}\right)}
$$

where $E_{\text {app }}$ is the apparent modulus of elasticity as shown in Equation (7) and $E_{\text {modal }}$ is the modulus of elasticity measured from modal testing.

\section{Test Results}

The results from the different laboratory tests are presented in this section. The modal tests on the laminates provide the basis to form "homogeneous" single-layers. In turn, the single-layer tests provide the basis for the calculation of the theoretical shear stiffness values based on Timoshenko beam theory and shear analogy method. The CLT panel tests are the basis for the determination of the shear stiffness values based on planar and flexure tests $\left((G A)_{\text {planar }}\right.$ and $\left.(G A)_{\text {eff,flex }}\right)$.

\subsection{Single-Layer Tests}

The formed single-layer panels were tested in modal and static testing. A total of 55 FEG and 54 SEG single-layer panels were tested. The modulus of elasticity parallel to the grain $\left(E_{11}\right)$, modulus of elasticity perpendicular to the grain $\left(E_{22}\right)$ and in-plane shear modulus $\left(G_{12}\right)$ were evaluated. The $E_{22}$ and $G_{12}$ values of the SEG single-layer panels could not be evaluated in static testing since the local glue spots did not provide sufficient structural integrity for these tests. Table 2 gives an overview of the evaluated properties of the FEG and SEG single-layer panels. Furthermore, planar shear tests were undertaken to evaluate the out-of-plane shear properties parallel to the grain $\left(G_{13}\right)$ and perpendicular to the grain $\left(G_{23}\right)$ of the single layers. Six tests parallel to the grain and 18 tests perpendicular to the grain were undertaken. The results are shown in Table 2. 
Table 2. Single-layer properties.

\begin{tabular}{|c|c|c|c|c|c|c|c|c|}
\hline $\begin{array}{l}\text { Panel } \\
\text { Type }\end{array}$ & $\begin{array}{c}\text { Test } \\
\text { Method }\end{array}$ & $\begin{array}{l}\text { Average } \\
\& \text { StDev }\end{array}$ & $\begin{array}{l}\text { Density } \\
\left(\mathrm{kg} / \mathrm{m}^{3}\right)\end{array}$ & $\begin{array}{c}E_{11} \\
\left(\mathrm{~N} / \mathrm{mm}^{2}\right)\end{array}$ & $\begin{array}{c}E_{22} \\
\left(\mathrm{~N} / \mathrm{mm}^{2}\right)\end{array}$ & $\begin{array}{c}G_{12} \\
\left(\mathrm{~N} / \mathrm{mm}^{2}\right)\end{array}$ & $\begin{array}{c}G_{13} \\
\left(\mathrm{~N} / \mathrm{mm}^{2}\right)\end{array}$ & $\begin{array}{c}G_{23} \\
\left(\mathrm{~N} / \mathrm{mm}^{2}\right)\end{array}$ \\
\hline \multirow{2}{*}{ FEG } & Modal & $\begin{array}{l}\text { Average } \\
\text { StDev }\end{array}$ & $\begin{array}{c}465.9 \\
25.7\end{array}$ & $\begin{array}{c}10,919.6 \\
1776.9\end{array}$ & $\begin{array}{c}283.6 \\
55.5\end{array}$ & $\begin{array}{c}696.5 \\
94.9\end{array}$ & - & - \\
\hline & Static & $\begin{array}{c}\text { Average } \\
\text { StDev }\end{array}$ & $\begin{array}{c}465.9 \\
25.7\end{array}$ & $\begin{array}{c}10,965.3 \\
1837.7\end{array}$ & $\begin{array}{c}264.4 \\
74.5\end{array}$ & $\begin{array}{l}796.0^{1} \\
101.5^{1}\end{array}$ & $\begin{array}{l}753.4^{2} \\
80.1^{2}\end{array}$ & $\begin{array}{l}261.8^{3} \\
92.6^{3}\end{array}$ \\
\hline \multirow{2}{*}{ SEG } & Modal & $\begin{array}{l}\text { Average } \\
\text { StDev }\end{array}$ & $\begin{array}{c}401.2 \\
19.8\end{array}$ & $\begin{array}{c}10,152.0 \\
1428.8\end{array}$ & $\begin{array}{l}60.8 \\
18.5\end{array}$ & $\begin{array}{c}482.8 \\
68.2\end{array}$ & - & - \\
\hline & Static & $\begin{array}{c}\text { Average } \\
\text { StDev }\end{array}$ & $\begin{array}{c}401.2 \\
19.8\end{array}$ & $\begin{array}{c}10,655.5 \\
1528.3\end{array}$ & - & - & $\begin{array}{l}874.5^{2} \\
143.9^{2}\end{array}$ & $\begin{array}{l}188.5^{3} \\
74.0^{3}\end{array}$ \\
\hline
\end{tabular}

${ }^{1}$ Results based on 28 FEG specimens. ${ }^{2}$ Results based on 3 FEG specimen and/or 3 SEG specimen. ${ }^{3}$ Results based on 9 FEG specimen and/or 9 SEG specimen.

\subsection{CLT Panel Tests}

The results for the moduli of elasticity from the modal and static tests are compared with calculated effective modulus of elasticity, $E_{e f f}$, based on the single-layer properties. The calculated effective modulus of elasticity is based on the bending stiffness calculated by Equation (1). The calculated bending stiffness is divided by the second moment of inertia of the overall cross-section. Equation (14) shows the calculation of the effective modulus of elasticity.

$$
E_{e f f}=\frac{(E I)_{e f f}}{I}=\frac{(E I)_{e f f}}{b t^{3} / 12}
$$

where $(E I)_{e f f}$ is the effective bending stiffness as calculated in Equation (1), $b$ is the width of the specimen and $t$ is the thickness of the specimen.

Due to the layered structure of CLT with alternating grain directions, the deformation behavior of CLT is strongly influenced by shear deformation. Figure 6 shows the theoretical influence of shear on the deformation behavior of 3- and 5-layer CLT panels parallel and perpendicular to the grain in three-point bending, under the assumption of $E_{/ / /} / E_{\perp}$ and $G_{/ /} / G_{\perp}$ ratios of 30 and 10 respectively. The figure shows that the portion of shear deformation within the overall deformation increases with decreasing span-to-thickness ratios. Furthermore, it can be seen that the effects of shear deformation are stronger in the direction parallel to the grain. For the given span-to-thickness ratios in Table 1, the influence of shear on the 3-layer CLT deformation can be estimated as about $65 \%$ parallel to the grain and $5.4 \%$ perpendicular to the grain. For the 5-layer panels the influence of shear is about $75 \%$ parallel to the grain and $60 \%$ perpendicular to the grain.

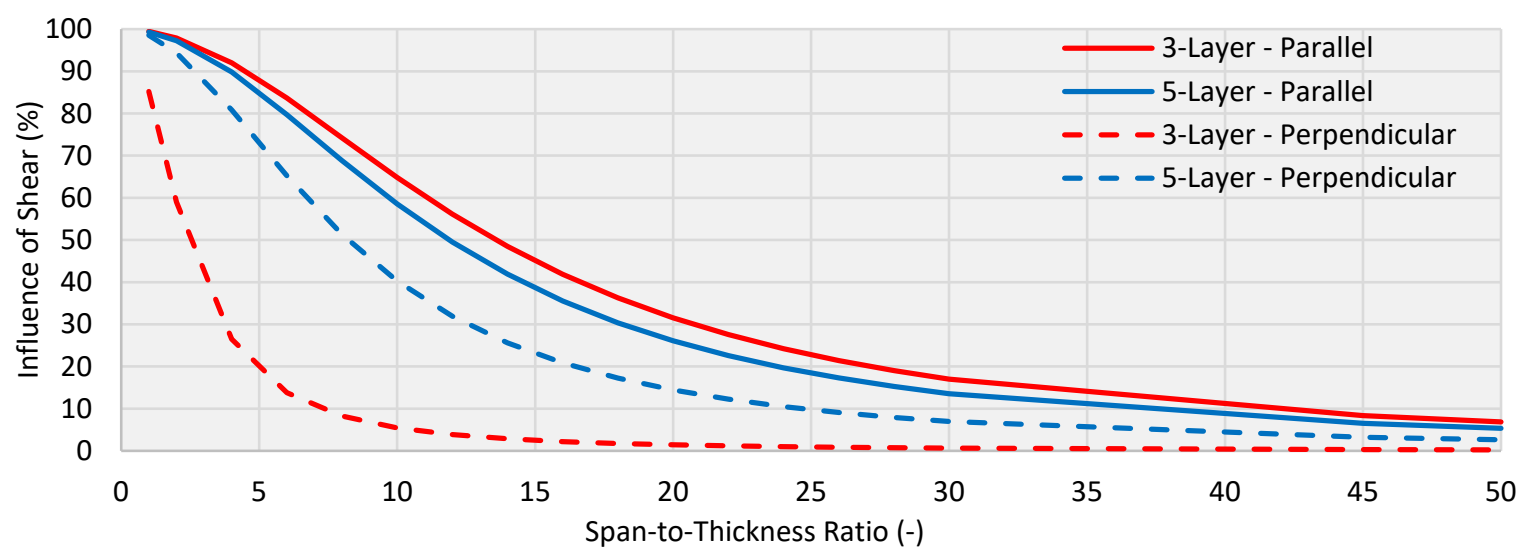

Figure 6. Influence of shear on 3- and 5-layer deformation in three-point bending. 
Table 3 presents the different measured global properties of the 3- and 5-layer CLT panels. The table presents the average values of a group, as well as the related standard deviations (in brackets). The measured properties are the modulus of elasticity parallel to the grain of the outer layers $E_{11}$, the modulus of elasticity perpendicular to the grain of the outer layers $E_{22}$, the in-plane shear modulus $G_{12}$, the out-of-plane shear modulus parallel to the grain of the outer layers $G_{13}$ and out-of-plane shear modulus perpendicular to the grain of the outer layers $G_{23}$, as well as the density.

Table 3. Global 3- and 5-layer CLT average properties and standard deviations (in brackets).

\begin{tabular}{|c|c|c|c|c|c|c|c|c|}
\hline & Panel Type & & $\begin{array}{l}\text { Density } \\
\left(\mathrm{kg} / \mathrm{m}^{3}\right)\end{array}$ & $\begin{array}{c}E_{11} \\
\left(\mathrm{~N} / \mathrm{mm}^{2}\right)\end{array}$ & $\begin{array}{c}E_{22} \\
\left(\mathrm{~N} / \mathrm{mm}^{2}\right)\end{array}$ & $\begin{array}{c}G_{12} \\
\left(\mathrm{~N} / \mathrm{mm}^{2}\right)\end{array}$ & $\begin{array}{c}G_{13} \\
\left(\mathrm{~N} / \mathrm{mm}^{2}\right)\end{array}$ & $\begin{array}{c}G_{23} \\
\left(\mathrm{~N} / \mathrm{mm}^{2}\right)\end{array}$ \\
\hline \multirow{6}{*}{ 3-Layer } & \multirow{3}{*}{$\begin{array}{l}F \\
E \\
G\end{array}$} & Calc. & \multirow{3}{*}{$\begin{array}{l}482 \\
(13)\end{array}$} & $\begin{array}{c}10,601 \\
(522)\end{array}$ & $\begin{array}{l}627 \\
(95)\end{array}$ & $\begin{array}{l}725 \\
(93)\end{array}$ & - & - \\
\hline & & Modal & & $\begin{array}{c}11,471 \\
(703)\end{array}$ & $\begin{array}{c}783 \\
(118)\end{array}$ & $\begin{array}{c}853 \\
(111)\end{array}$ & - & - \\
\hline & & Static & & $\begin{array}{c}3502 \\
(1182)\end{array}$ & $\begin{array}{l}612 \\
(96)\end{array}$ & - & $\begin{array}{l}231 \\
(47)\end{array}$ & $\begin{array}{l}165 \\
(54)\end{array}$ \\
\hline & \multirow{3}{*}{$\begin{array}{l}S \\
E \\
G\end{array}$} & Calc. & \multirow{3}{*}{$\begin{array}{l}407 \\
(27)\end{array}$} & $\begin{array}{c}9736 \\
(1179)\end{array}$ & $\begin{array}{l}406 \\
(31)\end{array}$ & $\begin{array}{c}486 \\
(102)\end{array}$ & & \\
\hline & & Modal & & $\begin{array}{c}9216 \\
(1510)\end{array}$ & $\begin{array}{l}495 \\
(52)\end{array}$ & $\begin{array}{l}353 \\
(97)\end{array}$ & & \\
\hline & & Static & & $\begin{array}{l}2828 \\
(767)\end{array}$ & $\begin{array}{l}417 \\
(49)\end{array}$ & - & $\begin{array}{c}179 \\
(961)\end{array}$ & $\begin{array}{l}115 \\
(24)\end{array}$ \\
\hline \multirow{6}{*}{ 5-Layer } & \multirow{3}{*}{$\begin{array}{l}F \\
E \\
G\end{array}$} & Calc. & \multirow{3}{*}{$\begin{array}{l}480 \\
(11)\end{array}$} & $\begin{array}{c}9403 \\
(1780)\end{array}$ & $\begin{array}{l}2649 \\
(440)\end{array}$ & $\begin{array}{l}679 \\
(79)\end{array}$ & & \\
\hline & & Modal & & $\begin{array}{l}12,736 \\
(3246)\end{array}$ & $\begin{array}{l}3192 \\
(448) \\
\end{array}$ & $\begin{array}{c}904 \\
(142)\end{array}$ & & \\
\hline & & Static & & $\begin{array}{c}1344 \\
(80)\end{array}$ & $\begin{array}{l}930 \\
(48)\end{array}$ & - & $\begin{array}{l}212 \\
(86)\end{array}$ & $\begin{array}{l}149 \\
(38)\end{array}$ \\
\hline & \multirow{3}{*}{$\begin{array}{l}S \\
E \\
G\end{array}$} & Calc. & \multirow{3}{*}{$\begin{array}{l}405 \\
(10)\end{array}$} & $\begin{array}{c}9264 \\
(1003)\end{array}$ & $\begin{array}{l}2378 \\
(298)\end{array}$ & $\begin{array}{l}485 \\
(36)\end{array}$ & & \\
\hline & & Modal & & $\begin{array}{l}13,355 \\
(3430)\end{array}$ & $\begin{array}{l}2338 \\
(481) \\
\end{array}$ & $\begin{array}{c}361 \\
(119)\end{array}$ & & \\
\hline & & Static & & $\begin{array}{c}1078 \\
(57)\end{array}$ & $\begin{array}{l}712 \\
(67)\end{array}$ & - & $\begin{array}{l}133 \\
(51)\end{array}$ & $\begin{array}{l}111 \\
(33)\end{array}$ \\
\hline
\end{tabular}

\subsection{Shear Stiffness Results}

Theoretical shear stiffness values based on Timoshenko beam theory (TBT) (Equation (5)) and shear analogy method (SA), (Equation (6)), were calculated for the 3- and 5-layer CLT panels. These shear stiffness values were calculated based on the moduli of elasticity of the single-layers ( $E_{11}$ and $\left.E_{22}\right)$. For both, the Timoshenko beam theory and the shear analogy method, two shear stiffness values were calculated. One was based on commonly used property ratios $G_{13}=E_{11} / 16$ and $G_{23}=G_{13} / 10$ $\left(\mathrm{TBT}_{\text {(ratio) }}\right.$ and $\left.\mathrm{SA}_{(\text {ratio) }}\right)$, the other one was based on the overall average out-of-plane shear moduli parallel to the grain $\left(G_{13}\right)$ and the average out-of-plane shear moduli perpendicular to the grain $\left(G_{23}\right)$ of the corresponding group (FEG or SEG) from the planar shear tests $\left(\mathrm{TBT}_{(\text {test }}\right.$ and $\left.\mathrm{SA}_{(\text {test })}\right)$. The used shear modulus parallel to the grain on a single-layer was $G_{13}=813.9 \mathrm{~N} / \mathrm{mm}^{2}$, in the minor direction shear moduli of $G_{23}=261.8 \mathrm{~N} / \mathrm{mm}^{2}$ for FEG layer panels and $G_{23}=188.5 \mathrm{~N} / \mathrm{mm}^{2}$ for SEG layer panels were used. The overall average out-of-plane shear modulus parallel to the grain $\left(G_{13}\right)$ was used for both panel types since it is assumed that the existence of edge-gluing has no negative effect on the $G_{13}$ value even though the FEG group shows a smaller $G_{13}$ value compared to the SEG group. 
The calculated values were compared with the shear stiffness values determined by planar shear tests (Planar) (Equation (10)) and the flexure tests (Flex) (Equation (13)).

Figures 7-10 present the different calculated shear stiffness values as well as the determined stiffness values from laboratory tests. Figure 7 shows the results for the 3-layer panels in the major strength direction. The shear stiffness values calculated by Timoshenko beam theory and shear analogy based of the commonly used ratios agree fairly well with each other with the shear analogy method values being slightly lower. The difference between the values calculated by Timoshenko beam theory and shear analogy method increases with the decrease in $G_{13} / G_{23}$ ratio as it can be seen in calculated values based on the single-layer planar shear tests $\left(\mathrm{TBT}_{(\text {test })}\right.$ and $\left.\mathrm{SA}_{(\text {test })}\right)$. The shear stiffness evaluated by planar shear tests shows better agreement with the calculated values based on the single-layer planar shear tests, with the planar shear test values generally showing lower values than the calculated values. The FEG layer based results produce more consistent values compared to the SEG layer based tests. The stiffness values determined by flexure tests show better agreement with the values calculated by common ratios, while showing relatively low values in general.

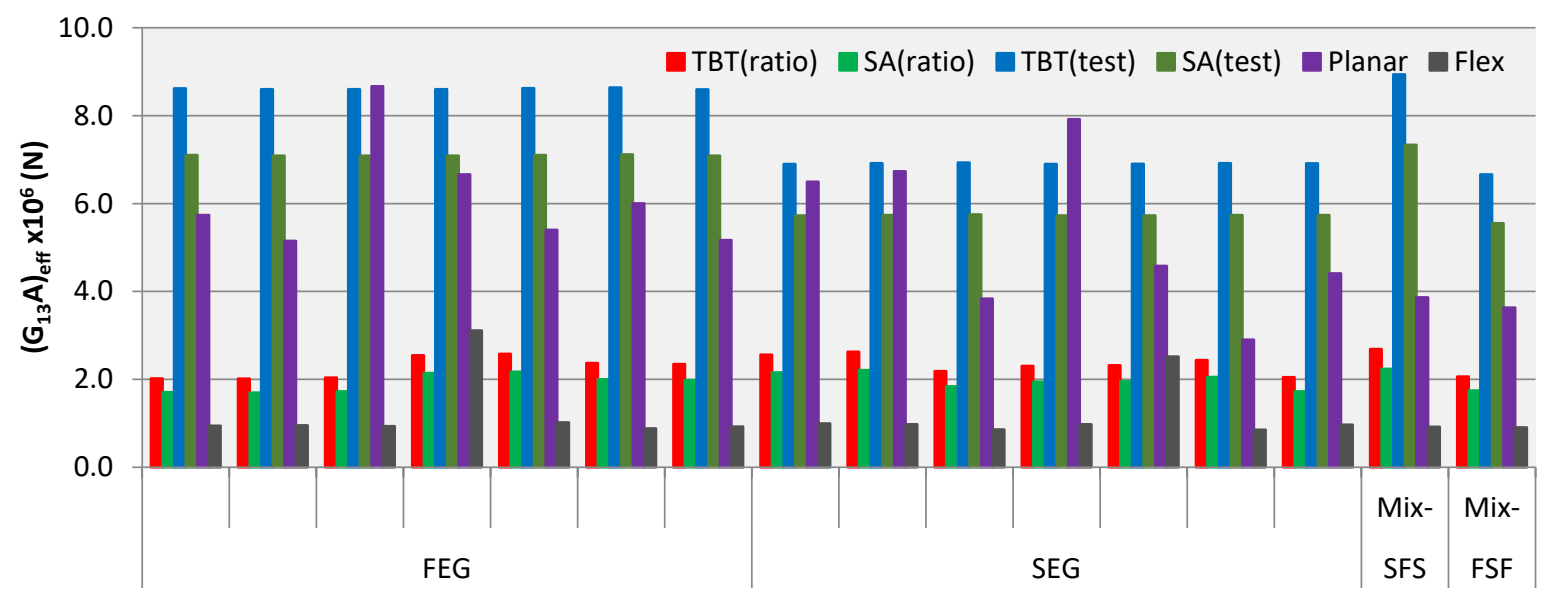

Figure 7. Shear stiffness values of 3-layer CLT in the major direction.

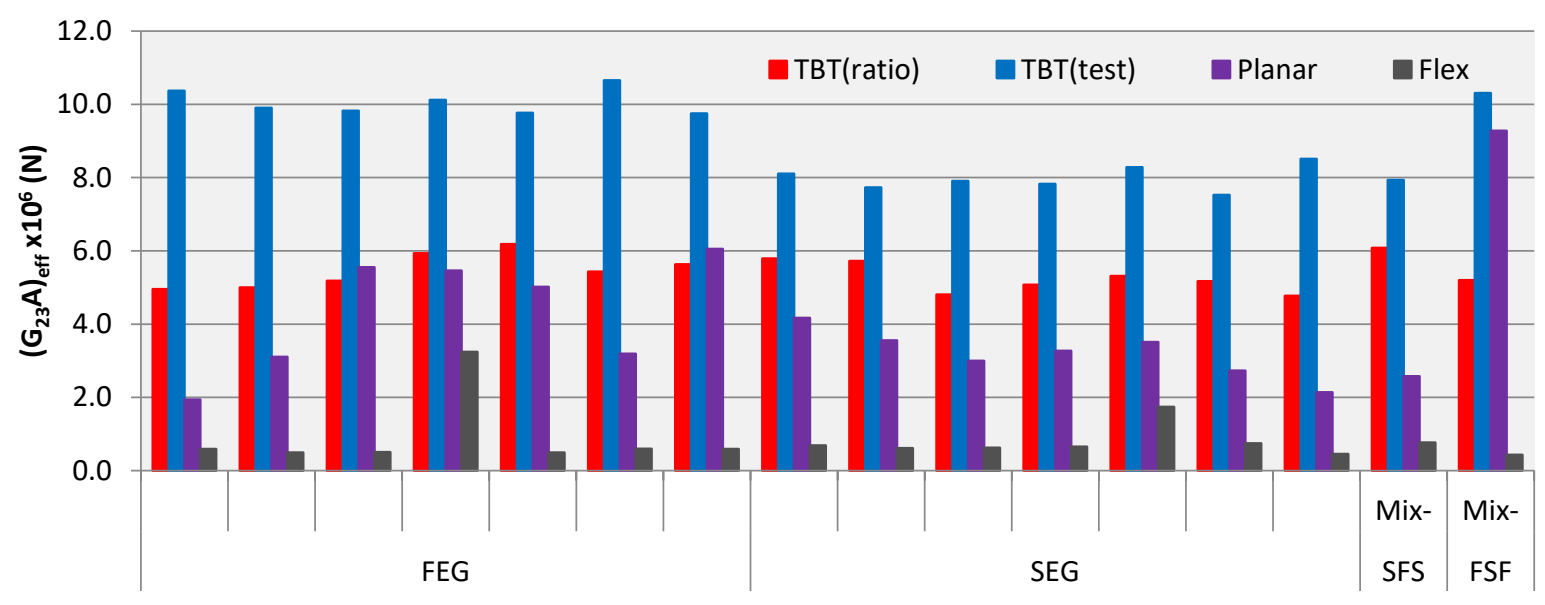

Figure 8. Shear stiffness values of 3-layer CLT in the minor direction. 


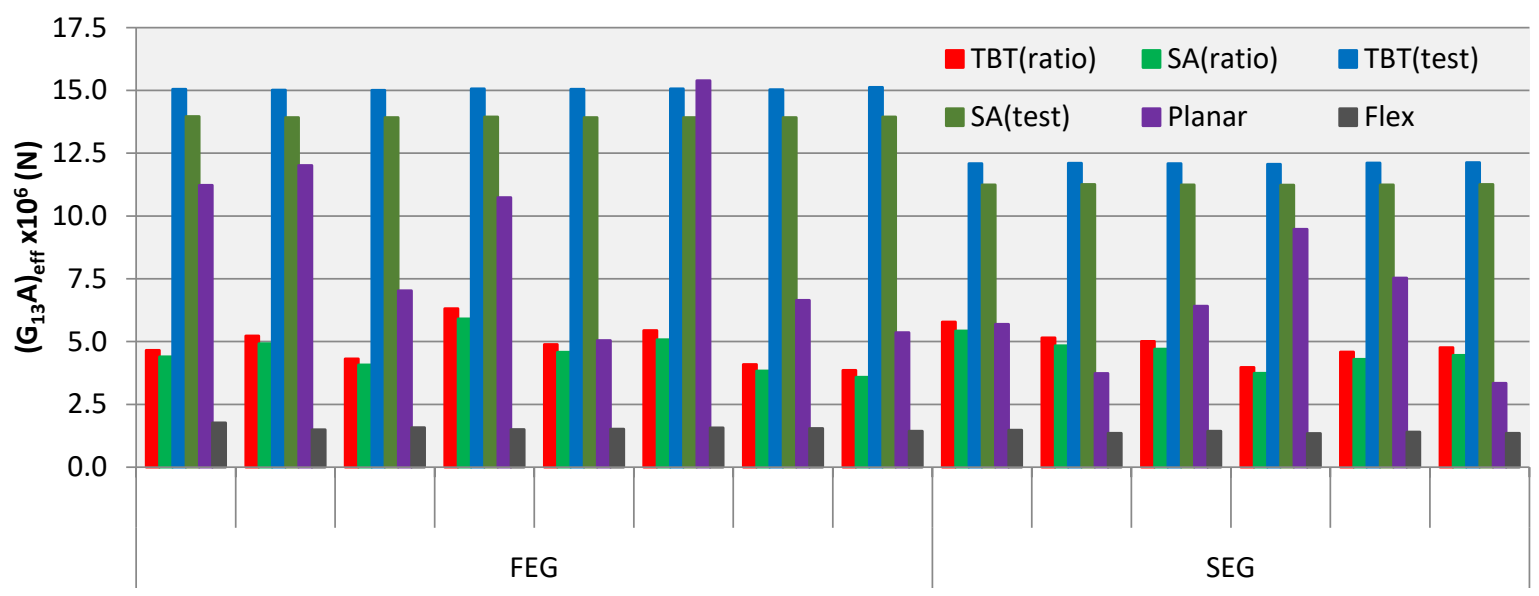

Figure 9. Shear stiffness values of 5-layer CLT in the major direction.

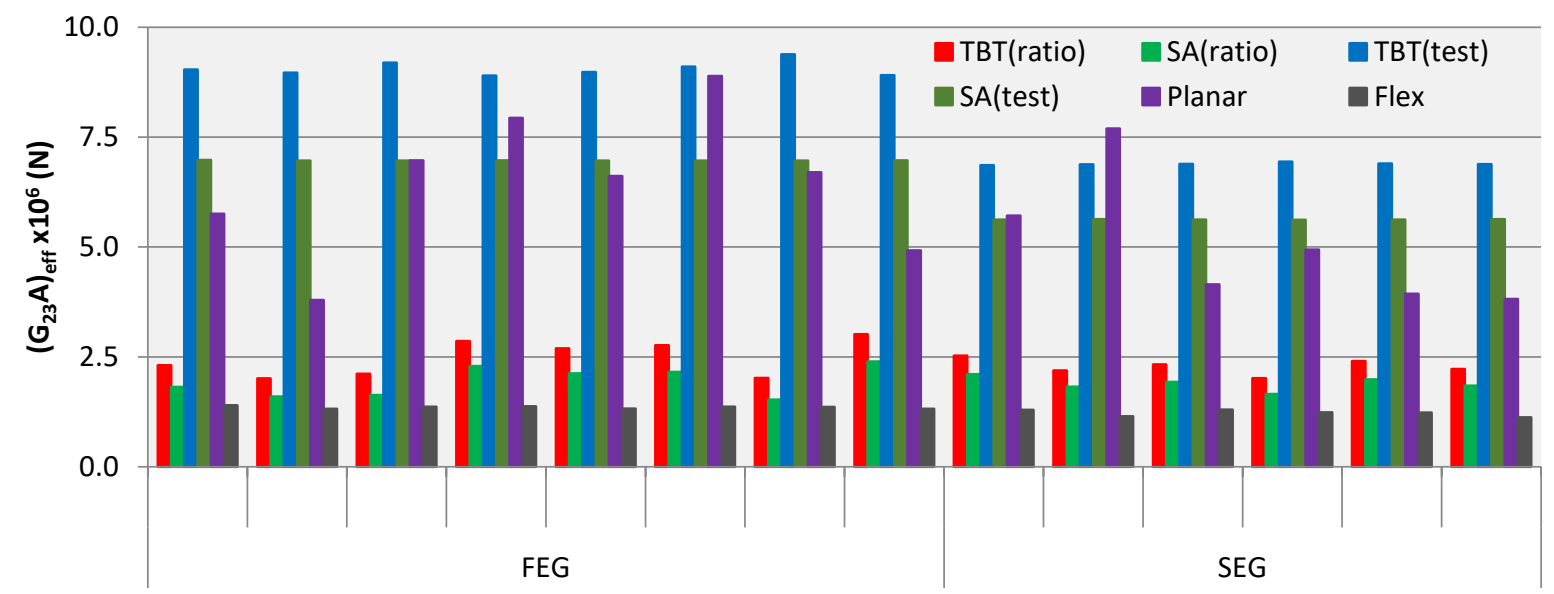

Figure 10. Shear stiffness values of 5-layer CLT in the minor direction.

Figure 8 shows the results for the 3-layer panels in the minor strength direction. Only calculated values from the Timoshenko beam theory are presented for the minor direction of the 3-layer CLT panels since the shear analogy method cannot calculate stiffness values for this case. For the minor direction of a 3-layer CLT the value $a$, the distance of the centre points of the most outer layers parallel to the considered direction, is zero and therefore no values can be calculated. As before, the results between the values calculated based on commonly used ratios and single-layer test results differ significantly. For the minor direction, the test results from the planar shear tests agree better with the calculated values utilizing the commonly used stiffness ratios. Like in the major direction the FEG layers show more consistent results. As before, the results from the flexure tests are significantly lower.

Figure 9 presents the evaluated shear stiffness values for the 5-layer CLT panels parallel to the grain of the outer layers. Similar to the major direction of the 3-layer CLT (Figure 7) The Timoshenko beam theory and the shear analogy method show good agreement with each other for the different calculation bases (commonly used ratios and single-layer shear tests). These two different calculation bases produce significant differences within the different calculation methods. The planar shear tests results of the FEG layer based CLT panels show higher values compared to the SEG layer based CLT panels. Again, the results from the flexure tests are significantly lower.

Figure 10 gives the results for the 5-layer CLT panels in the direction perpendicular to the grain of the outer layer. The agreement between the two calculation methods for the commonly used stiffness ratios is good, the difference between the results from the two methods becomes larger with a decrease in $G_{13} / G_{23}$ ratio. The planar shear tests results show better agreement with the values calculated based 
on the single-layer planar shear test results. The results from the flexure tests are significantly lower but show reasonable agreement with the values calculated by the commonly used stiffness ratios.

\section{Discussion}

From the presented results, several observations can be made. First, it can be seen that the two calculation approaches yield similar shear stiffness values, especially at lower $G_{13} / G_{23}$ ratio as it can be seen in the results using the commonly used stiffness ratios $\left(\mathrm{TBT}_{\text {(ratio) }}\right.$ and $\left.\mathrm{SA}_{(\text {ratio) }}\right)$. It can be seen that the two approaches lead to similar shear stiffness values with the Timoshenko beam theory usually yielding higher shear stiffness values. Furthermore, it can be seen in the figures showing the results for the major strength direction (Figures 7 and 9) that the agreement of the two methods increases with the number of layers. Figures $7-10$ show the strong influence of the $G_{13} / G_{23}$ ratio on the comparison of the two calculation methods. It can be seen that the two different property sets used for the calculations, namely the commonly used property ratios $G_{13}=E_{11} / 16$ and $G_{23}=G_{13} / 10$ and the average single-layer $G_{13}$ and $G_{23}$ values from laboratory tests show significant differences. The main reason is that the properties evaluated in the planar shear tests are usually substantially higher than the ones determined by the property ratios. For the average modulus of elasticity $E_{11}$ of a single-layer evaluated in the modal tests the property ratios yield shear moduli of $G_{13}=658.5 \mathrm{~N} / \mathrm{mm}^{2}$ and $G_{23}=65.9 \mathrm{~N} / \mathrm{mm}^{2}$, while the average values from the planar shear test are $G_{13}=813.9 \mathrm{~N} / \mathrm{mm}^{2}$ and $G_{23}=261.8 \mathrm{~N} / \mathrm{mm}^{2}$ for FEG layer panels and $G_{23}=188.5 \mathrm{~N} / \mathrm{mm}^{2}$ for SEG layer panels. Based on the planar shear test results the property ratio based approach leads to about $21 \%$ lower $G_{13}$ values and $75 \%$ (FEG) to $66 \%$ (SEG) lower $G_{23}$ values.

Table 4 presents a comparison between the calculated shear stiffness values based on the Timoshenko beam theory and the shear analogy method and the shear stiffness values evaluated based on flexure tests, the results from the planar shear tests are chosen as the base for the comparison. The table shows the average values (Avg.) of the 3- and 5-layer CLT in the major and minor direction. Further, the standard deviation (StDev) is displayed. Figure 11 presents the average data from Table 4 in a graph. From Table 4 and Figure 11 it can be seen that the calculated values based on the commonly used property ratios yield lower results compared to the values evaluated by the planar shear tests, with exception of the values based on the Timoshenko beam theory for the 3-layer CLT in the minor direction. The results based on the single-layer planar shear tests are higher than the ones evaluated by the CLT planar shear tests. Based on this it appears that the $G_{13}$-to- $G_{23}$ ratios between 3.1 (for FEG) and 3.6 (for SEG) resulting from the single-layer planar shear tests could be lower than the ratios found in the layers in the actual tested CLT panels. The main driver is possibly the relatively high $G_{23}$ values of $261.8 \mathrm{~N} / \mathrm{mm}^{2}$ for the FEG panels and $188.5 \mathrm{~N} / \mathrm{mm}^{2}$ for the SEG panels. These values are significantly higher that the $G_{23}$ values commonly used in design. A lower $G_{13}$-to- $G_{23}$ ratio leads to higher shear stiffness value in both, major and minor direction. Other research projects have suggested $G_{23}$ values around $135 \mathrm{~N} / \mathrm{mm}^{2}$ for the same and similar materials [16,17], which would lead to a $G_{13}-$ to- $_{23}$ ratio of around 6.0 and therefore a better agreement to the shear stiffness values evaluated in the laboratory tests. It is interesting to see that the results from the flexure tests are not only lower than the results from the planar shear tests but that the percentage is consistently around $-77 \%$ at a relatively low level of standard deviation. If this value can be confirmed by further test the shear stiffness of multi-layer CLT panels with symmetrical layup and constant layer thickness could be estimated by a combination of modal and bending test, which would lead to significantly lower testing efforts compared to the planar shear tests. 
Table 4. Comparison of calculated and laboratory shear correction factors.

\begin{tabular}{|c|c|c|c|c|c|c|c|}
\hline & Panel Type & & $\begin{array}{c}\mathrm{TBT}_{(\text {(ratio) }} / \text { Planar } \\
(\%)\end{array}$ & $\underset{(\%)}{\mathrm{SA}_{(\text {ratio) }} / \text { Planar }}$ & $\begin{array}{c}\mathrm{TBT}_{(\text {test) }} / \text { Planar } \\
(\%)\end{array}$ & $\begin{array}{c}\mathrm{SA}_{(\text {test }} / \mathrm{Planar} \\
(\%)\end{array}$ & Flex/Planar (\%) \\
\hline \multirow{6}{*}{ Major } & \multirow{2}{*}{ 3-Layer } & Avg. & -55.7 & -61.0 & 53.3 & 26.8 & -77.3 \\
\hline & & StDev & 15.1 & 12.6 & 43.3 & 35.8 & 12.1 \\
\hline & \multirow{2}{*}{ 5-Layer } & Avg. & -26.2 & -30.8 & 106.6 & 91.6 & -77.7 \\
\hline & & StDev & 34.3 & 32.1 & 83.0 & 76.9 & 9.0 \\
\hline & \multirow{2}{*}{ Total } & Avg. & -40.8 & -46.9 & 78.2 & 57.0 & -77.5 \\
\hline & & StDev & 29.2 & 27.9 & 69.2 & 66.3 & 10.6 \\
\hline \multirow{6}{*}{ Minor } & \multirow{2}{*}{ 3-Layer } & Avg. & 54.8 & - & 159.4 & - & -77.5 \\
\hline & & StDev & 53.9 & - & 103.8 & - & 14.6 \\
\hline & \multirow{2}{*}{ 5-Layer } & Avg. & -56.3 & -64.8 & 47.7 & 16.6 & -76.2 \\
\hline & & StDev & 12.1 & 10.3 & 38.4 & 30.7 & 6.3 \\
\hline & \multirow{2}{*}{ Total } & Avg. & 2.9 & -64.8 & 107.3 & 16.6 & -76.9 \\
\hline & & StDev & 68.9 & 10.3 & 97.2 & 30.7 & 11.3 \\
\hline
\end{tabular}

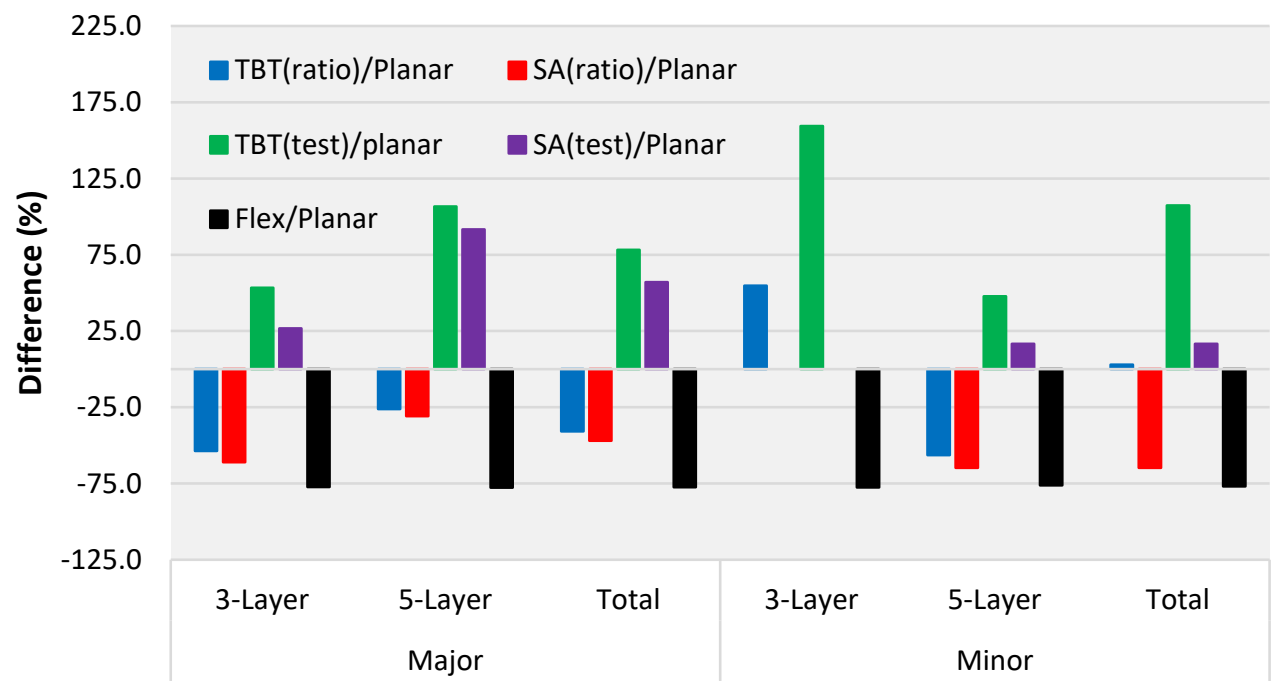

Figure 11. Calculated and laboratory shear stiffness values compared to planar shear tests.

\section{Conclusions}

Based on the theoretical analysis it can be seen that the shear stiffness values in the major and minor directions are sensitive to the $G_{13}$-to- $G_{23}$ ratio for both the Timoshenko beam theory and the shear analogy. It can also be seen how the two calculation approaches lead to good agreement compared to each other in the major strength direction and that the agreement increases with an increasing number of layers. In the minor direction, the approaches show less agreement and in the case of 3-layer CLT no comparison was possible since no stiffness could be calculated based on the shear analogy. The shear stiffness values evaluated in the laboratory tests show different results, while the flexure tests lead to the lowest values, the results from the planar shear tests agree best with values calculated based on commonly used property ratios. A reason could be that the evaluated single-layer shear properties are significantly higher than the ones of the layers within the actual tested CLT. Particularly the evaluated single-layer rolling shear modulus $\left(G_{23}\right)$ is high, leading to low $G_{13}$-to- $G_{23}$ ratios and therefore higher shear correction factors. The constant ratio between the results from flexure tests and the planar shear tests could potentially be used for the evaluation of the planar shear stiffness of CLT. To evaluate the validity of the experimental approach of combining modal and bending tests to measure shear stiffness of CLT further evaluation with more consistent material would be needed.

Author Contributions: Conceptualization, J.N. and Y.-H.C.; Methodology, J.N.; Validation, J.N. and Y.-H.C.; Formal Analysis, J.N.; Investigation, J.N.; Resources, J.N.; Data Curation, J.N.; Writing-Original Draft Preparation, J.N.; Writing-Review \& Editing, J.N. and J.Z.; Visualization, J.N.; Supervision, Y.-H.C.; Project Administration, J.N.; Funding Acquisition, Y.-H.C. 
Funding: This research was funded by Natural Sciences and Engineering Research Council of Canada (NSERC) through the NEWBuildS (Network for Engineered Wood-based Building Systems) network grant number (NETGP386472-09).

Acknowledgments: The authors would like to thank the Natural Sciences and Engineering Research Council of Canada (NSRC), CMHC International, Construction Portfolio of the National Research Council and FPInnovations. This research is supported through funding to the NSERC Strategic Research Network on Innovative Wood Products and Building Systems.

Conflicts of Interest: The authors declare no conflict of interest. The funders had no role in the design of the study; in the collection, analyses, or interpretation of data; in the writing of the manuscript and in the decision to publish the results.

\section{References}

1. Brandner, R.; Flatscher, G.; Ringhofer, A.; Schickhofer, G.; Thiel, A. Cross laminated timber (CLT): Overview and development. Eur. J. Wood Wood Prod. 2016, 74, 331-351. [CrossRef]

2. O'Ceallaigh, C.; Sikora, K.S.; McPolin, D.O.; Harte, A.M. The Influence of Panel Lay-up on the Characteristic Bending and Rolling Shear Strength of CLT. Buildings 2018, 8, 114. [CrossRef]

3. Ehrhart, T.; Brandner, R.; Schickhofer, G.; Frangi, A. Rolling Shear Properties of some European Timber Species with Focus on Cross Laminated Timber (CLT): Test Configuration and Parameter Study. In Proceedings of the 48th Meeting of the International Network on Timber Engineering Research (INTER 2015), Šibenik, Croatia, 24-27 August 2015; pp. 61-76.

4. CEN. Eurocode 5 Design of Timber Structures. Part 1-1: General Common Rules and Rules for Buildings. EN 1995-1-1; European Committee for Standardization: Brussels, Belgium, 2006.

5. Augustin, M.; Bogensperger, T.; Schickhofer, G. BSPhandbuch: Holz-Massivbauweise in Brettsperrholz-Nachweise auf Basis des Neuen EuropäIschen Normenkonzepts; Verlag der Technischen Univiversitaet Graz: Graz, Austria, 2010.

6. Kreuzinger, H. Platten, Scheiben und Schalen-Ein Berechnungsmodell für gängige Statikprogramme. Bau mit Holz 1999, 1, 34-39.

7. Vlachoutsis, S. Shear correction factors for plates and shells. Int. J. Numer. Methods Eng. 1992, 33, 1537-1552. [CrossRef]

8. Timoshenko, S.P. On the correction of shear of the differential equation for transverse vibrations of prismatic bars. Lond. Edinb. Dublin Philos. Mag. J. Sci. 1921, 41, 744-746. [CrossRef]

9. Reissner, E. The effect of transverse shear deformation on the bending elastic plates. J. Appl. Mech. 1945, 12, 69-77.

10. Mindlin, R.D. Thickness-shear and flexural vibrations of crystal plates. J. Appl. Phys. 1951, 22, $316-323$. [CrossRef]

11. Cowper, G.R. The shear coefficient in Timoshenko's beam theory. J. Appl. Mech. 1966, 33, 335-340. [CrossRef]

12. Chui, Y.H. Simultaneous Evaluation of Bending and Shear Moduli of Wood and the Influence of Knots on these Parameters. Wood Fiber Sci. 1991, 25, 125-134. [CrossRef]

13. Larsson, D. Using Modal Analysis for Estimation of Anisotropic Material Constants. J. Eng. Mech. 1997, 123, 222-229. [CrossRef]

14. ASTM. Standard Test Methods of Static Tests of Lumber in Structural Sizes-Designation D198; ASTM International: West Conshohocken, PA, USA, 2015.

15. ASTM. Standard Test Methods for Structural Panels in Planar Shear (Rolling Shear)_Designation D2718; ASTM International: West Conshohocken, PA, USA, 2000.

16. Chui, Y.H.; Gong, M. Evaluation of Planar Shear Properties of Cross Layer in Massive Timber Panel; Final Report \#: WSTC2013-015; Wood Science and Technology Centre, The University of New Brunswick: Fredericton, NB, Canada, 2015.

17. Zhou, Q. Development of Evaluation Methodology for Rolling Shear Properties in Cross Laminated Timber (CLT). Master's Thesis, University of New Brunswick, Fredericton, NB, Canada, 2013.

(C) 2018 by the authors. Licensee MDPI, Basel, Switzerland. This article is an open access article distributed under the terms and conditions of the Creative Commons Attribution (CC BY) license (http:/ / creativecommons.org/licenses/by/4.0/). 